\title{
THE PLACE OF ORGANISATIONAL CAPABILITIES IN STRATEGY FORMULATION AND IMPLEMENTATION: AN EXPLORATORY ANALYSIS
}

\author{
JULIANA B. AKAEGBU AND A. A. USORO
}

(Received 15 May 2017; Revision Accepted 7 July 2017)

\begin{abstract}
One of the most difficult things to do when venturing on a project or strategy, is how to start it. To implement a strategy is to change an organization or its processes of thinking, its processes of structure and its process of culture. Literature abound that one way or another has enunciated the benefits to be derived from maximizing organizational capability as a means of achieving competitive advantage. However, there is very little research done on the role capabilities play in the formulation and implementation of strategy. It is hereby pertinent to know that in order to implement a strategy, one needs to positively change and effectively feed his/her capabilities. The paper therefore seeks to explore extensively what capability and strategy are all about. It adopts the methodology of documentary analysis of relevant literature, making the research process exploratory and expository. The paper finds that there are nine stipulated steps in the process of formulating a strategy; the five essential capabilities and three levels of strategy were also noted. The need for organizational capability was emphatically emphasized, as well as, its place in strategy implementation. The paper therefore recommends amongst other things, that organization do periodic organizational capability audit in order to be always proactive enough to meet its goals and objectives and hence achieve competitive advantage.
\end{abstract}

KEYWORDS: Organisational capabilities, strategies, innovation and competitive advantage.

\section{INTRODUCTION}

Strategic issues are difficult to manage because of the subjectivity involved in their direction and diagnosis. The market for strategic issues in organization has to be made explicit and expressive. The level of capability goes a long way to help achieve this. Strategies are best driven by the organizational capabilities. They serve as the vehicles for translating individual concerns into organizational actions. Veskaisri, Chan and Pollard (2007) posit that, without a clearly defined strategy, a business will have no sustainable basis for creating and maintaining a competitive advantage in the industry where it operates.

As businesses compete with one another for customers, market share and revenue, they employ tactics according to deliberate strategies.
The process of shaping strategies and putting them into action is the responsibility of a business leadership. However, not all businesses have the same advantages when it comes to developing and employing strategy. An organization's competitive position is enabled by its ability to perform at a high level in differentiated ways, in short, its strategic success is enabled by distinctive organizational capabilities. Organisational capability is simply conceptualised as a business's ability to successfully utilise competitive strategies to survive and increase it value in an industry.

In today's dynamic world, we face the ongoing need to identify and develop new capabilities to respond to changing customer demands to competitive threats. Failing to do so can put an organization at risk of becoming obsolete. With the emergence of the knowledge

Juliana B. Akaegbu, Department of Business Management, Faculty of Management Sciences, University of Calabar, Calabar, Nigeria.

A. A. Usoro, Department of Business Management, Faculty of Management Sciences, University of Calabar, Calabar, Nigeria. 
era, it has become widely recognized that the intangible assets of an enterprise will be key to both its ability to create competitive advantage and to grow at an accelerated pace.

Organization exist as the vehicle through which resources are transformed into outputs, delivered to the necessary channels and desired goals and objectives achieved. However we look at it, we all need organization, at one point or another. There is therefore, this constant need to attend to the needs and demands of the customers. This can only be made possible when the capabilities of the organization are effectively and efficiently matched with the strategy in operation. Not much has been done in this direction, as to aid the appreciation of such capabilities in the life of an organization. This paper would contribute in filling this gap and foster proper understanding of the need to recognize the different capabilities that drive organisation's competitive advantage.

This research work examines the place of capabilities in strategy. The work is driven out of the desire to ascertain why organizational capabilities are not well appreciated in the formulation and implementation processes of strategy in organizations. This research is significant in numerous ways, it would bring to focus how organizational capabilities can be integrated into strategy processes in order to sustain and further improve effectiveness and efficiency. It would broaden our knowledge and increase our understanding regarding the subject under study base on the indebt literature expositions carried out. The content and context of organizational capabilities would be better appreciated to further improve on organizational productivity, through adequate utilization of the skills and experiences of employees. The research work would also serve as a medium of advancing the frontiers of knowledge for future researchers on the subject.

This paper adopts the methodology of documentary analysis of current literature which enhances critical and contextual examination of issues. Understanding how strategies are formulated and executed is of serious concern both to the people and the organization at large and as such attracts a plethora of scholarly commentaries. The paper therefore employs an exploratory and narrative methodology where critical review of existing puny literature was carried out. From the foregoing, the objective of this paper is to determine the place of capabilities (organizational or strategic) in the formulation and implementation of the strategic process.

The paper is therefore divided into five sections. The first section deals with the introduction, statement of the problem, significance of the study and methodology. The literature review which deals with the concepts of strategy, organizational capabilities and competitive strategy is presented in section two. Section three states the theoretical framework, the resource-based theory, and this is followed by section four as conclusion. Section five which is the last section outlines the recommendations.

\subsection{LITERATURE REVIEW \\ 2.1 Organizational capabilities}

This is simply the ability to perform or achieve certain actions or outcomes. These refer to a business's ability to successfully employ competitive strategies that allow it to survive and increase its value, overtime. They focus on the organization's assets, resources and market position, projecting how well it will be able to employ strategies in the future. There is no single method or universal metric for measuring or noting capabilities.

According to Smallwood and Ulrich (2004) organizational capabilities emerge when a company delivers on the combined competencies and abilities of its individuals. Organisational capabilities enable a company to turn its technical know-how into results. The ability of an enterprise to operate its day to day business as well as grow, adapt, and seek competitive advantage in the market place. The notion of capability has been extended into that of dynamic capabilities (Eisenhardt \& Martin, 2000).

If organization wants to improve its strategy execution rate, the first place to start is to agree on what really constitutes organizational capabilities. Capabilities comprise the ability and capacity of an organization expressed in terms of its human resources (quality, number, skills and experience), physical and material resources (machines, land, buildings), financial resources (money and credit), information resources (pool of knowledge, databases) and intellectual resources (copyrights, designs and patents etc). According to Gill and Delahaye (n.d.) organizational capability is defined as the embodied knowledge set that supports competitive advantage through innovation and flexibility gained by building alignment between the expertise of the individuals in the workforce. Kelchner (2016) sees organizational capability as the company's ability to manage resources, such 
as employees, effectively to gain an advantage over competitors. The company's organizational capability must focus on the business ability to meet customer's demand.

In a bid to articulate the capabilities required to create new opportunity to which financial capital can be applied, one must ensure that capabilities move to the centre of the organisation's strategic planning framework. The objectives, responses and business models of the enterprise can best be calibrated on the basis of the capabilities of the organization. The pace at which an organization can grow is, in large part, determined by the speed at which it can generate and configure its capabilities in response to challenges encountered in that changing market place. This is further explained in the capability dimension model presented below in Figure 1.

The rapid shift of customer preferences and market trends imposes a need for the acquisition of capabilities at an equally accelerated pace. Each competitor aims to shape the market to its strength in order to achieve a preeminent position. Organizational capabilities, according to Kelchner (2016) need to be unique to the organization to prevent application by competitors. Organizational capability plays an enormous role in the strategy of an organization: it aids in achieving strategic competitive advantage. This can be seen when an organization creates new capabilities and develop existing ones, they tend to maintain advantage over competition.

- There would be improved customer relationships which would in turn ensure continued growth in the market. The relationship between organization and its customers, as an organizational capability, affects sales, loyalty and reputation in the future business.

- Maintaining a talented workplace is an organizational capability that ensures they have the resources to improve continuously.

The capabilities an organization possesses would drive the attainment of its strategic plan. The different levels of strategy, directly or indirectly need the effective application of organizational capabilities in order to make a head way. Strategic plans provide guidance for the preparation of functional plans and business budget (Butuner, 2016). Functional strategic plans help in implementation by organising and activating specific units of the business strategy (marketing, finance, production, etc) in order to pursue the business strategy in daily activities. 


\subsubsection{Capability dimension model}

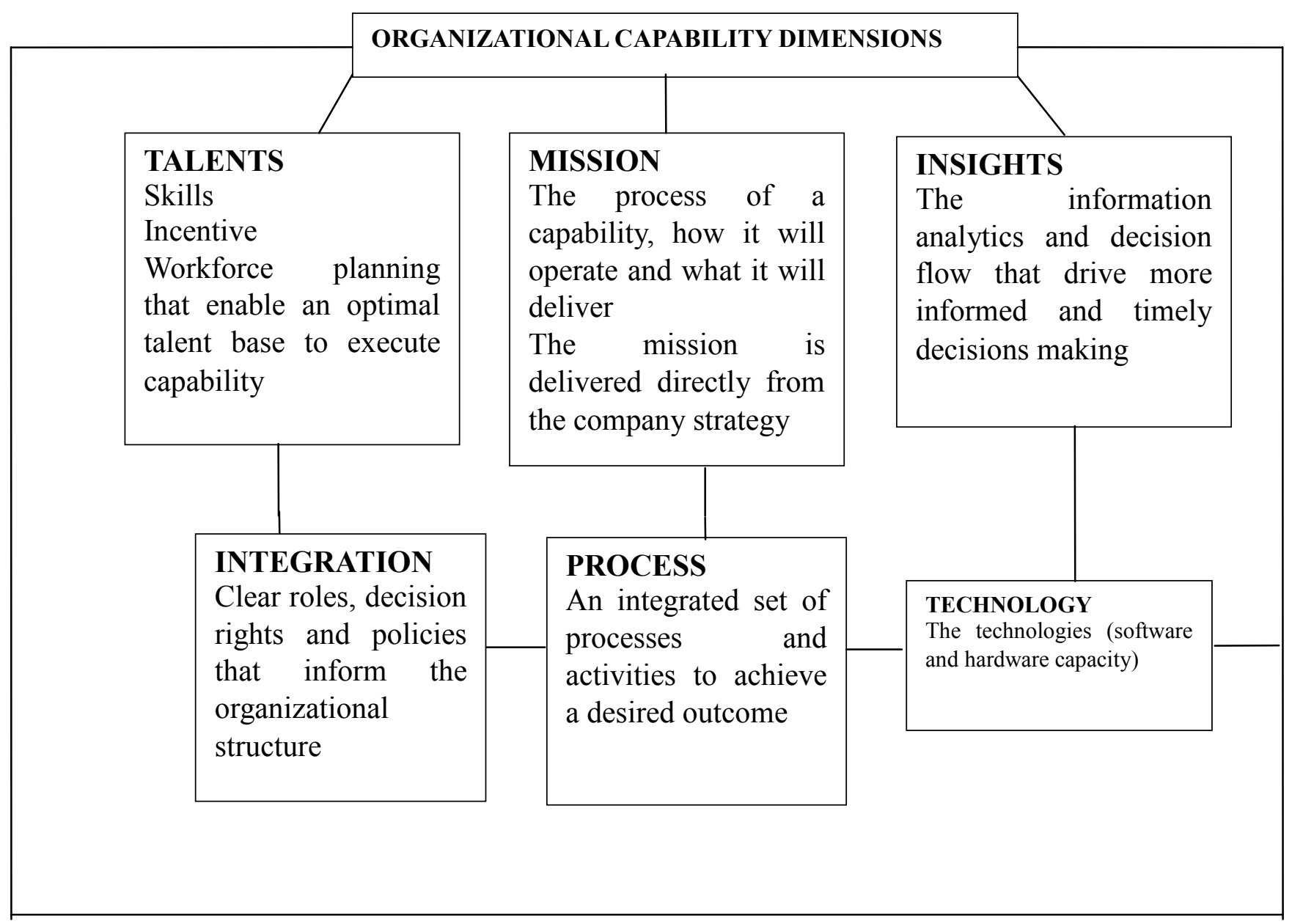

FIG. 1: Capability dimension model

Source: Authors' Conceptualized Model (2017)

This model shows some of the building blocks that, as an integrated set, serves as the foundation of an organizational capability. These elements can be helpful for execution to keep in mind when considering adapting or building capabilities needed to support company's strategy. Organizational capabilities transcend through the talents of the people in the organization, the mission (personal and collective) of the people and the insights they derive, being integrated into the existing technological processes as well as mode of operation in the system. The talents (skills and abilities) of an employee need to be first discovered, in other to be groomed to suit the best job role. The personal mission of the people needs to align with the general mission of the organization for productivity to be achieved. The capacity of the software and hardware needs to be in line with the capabilities of the people in the organization for efficient and effective purposes. Integration could come in form of training, workshops, technical exploration by either an inhouse expert or an out-sourced consultant. This would create a balance in understanding the processes and activities of the job to be carried out. All the variables in the model are interconnected and working together to achieve a 
capability synergy in the strategy formulation and implementation process of an organization.

\subsubsection{The significance of capability}

It is seen as a major component in remaining financially viable and growing despite the presence of competition in a free market. Many people tend to track strategic capability by trying to invest their money into businesses with reasonable chances of future success and growth. Employees do so in order to identify businesses that are stable and likely to go under or those that need to cut costs through layoffs. Business leaders on the one part, track it not only for their own companies but also for competitors to better understand the markets in which they operate. Also, financial analysts and government regulatory agencies on the other part, have interests in strategic capabilities since these play a role on how they value and monitor businesses.

Companies can improve on this track record by paying greater attention to the capabilities they need to successfully implement their strategy. Doing so, starts with understanding exactly what capabilities are and what they are not, as well as determining which capabilities are strategic i.e., are vital to the effective execution of a particular strategy which are core to competitive performance and which are fundamental abilities that a company must have to be a viable competitor. It also involves defining these capabilities, especially strategic ones, at a much fine level of detail to make it clear what the organization is hoping to accomplish with them.

\subsubsection{Five essential capabilities for organizational success}

Leadership: Silva (2016) sees leadership as easily effective if only it achieves its desired results. According to Bennis and Townsend (1995) leadership is the capacity to create a compelling vision and to translate vision into organizational realities. This is often perceived as a set of people at the top of the organization but it is actually a skill that can and should exist at every level. Leadership is the capability to inspire and motivate people to fulfil a mission. At the top of the organization, it includes directing others while at lower levels, it is accomplished through influencing others. Your company's leadership performance has a lot to do with how much the organization can accomplish in a given amount of time.
Collaboration: collaboration

can

reinvigorate organization by fully engaging employees, improving retention among them and increasing innovation. Kelly (2015) sees collaboration as a process with associated behaviour that can be taught and developed. A process governed by a set of norms and behaviours that maximize individual contribution while leveraging on the collective intelligence of everyone involved. Collaboration is also seen as a durable relationship that brings previously separate organizations into a new structure with commitment to a commonly defined mission, structure, or planning effort (Perrault, McClelland, Austin \& Sipeppert, 2011). This is the ability to work productively with others. At the low end of performance, collaboration provides the ability to effectively break down complex tasks and distribute the parts across a group of people or organisations. At higher levels of performance, collaboration creates organizational synergy, producing a performance boost where the whole is greater than the sum of its parts. Some organizations might require a higher degree of collaboration than others but every organization needs to collaborate at some level.

Adaptability: This refers to modification and alteration in the organization and its components in order to adjust to changes in the external environment (Sirinthon \& Phapruke, 2010). Adaptation, according to Dreyer and Gronhaug (2004) is seen as an important capability for survival and success. At no time in our history has adaptability been so critical. It is the organisation's ability to give up the existing skills, processes and technologies that have led to its past success and create new skills and approaches that ensure success tomorrow. Organisations need to be adaptable just to survive and highly adaptable if they expect to thrive.

Creativity: Creativity is the creation of a valuable, useful new product, service, idea, procedure, or process by individuals working together in a complex social system (Woodman, Sawyer \& Griffin, 1993). The problems we face today are much more complex and time critical than those of the past. They often cannot be solved by brute force alone. Creativity describes the organisation's ability to think differently and allow different thinking to influence day to day and strategic decisions. At the low end of the performance curve, organisations can be trapped in tradition and best practices, unable to solve persistent problems. At the high end, they are 
often challenged to prioritize among numerous new ideas.

Innovation: This goes beyond creativity to turning creative ideas into reality. Innovation culture increases decision making comprehensiveness via managerial activation (Moham, Voss \& Jimenez, 2017). It is the ability to translate a good concept into a compelling value proposition that others are willing to support and invest in. In the same way that national culture influences individuals' behavioural dispositions, so also organizational culture can activate one's innovative skills. When innovation ability is high, companies go beyond innovative products to design innovative processes, organizational structures, management practices and employment engagement approaches.

These five capabilities permeate the entire organization and every individual employee. Functional units can be established to act as centres of excellence that support and encourage the development of these capabilities, but that is not where the value resides. Yet each of these capabilities is essential for a high performing organization.

\subsection{Concept of strategy}

There is no unified meaning as to what strategy means. It is often used to refer to varying number of things. It could be seen as a plan or course of action or a set of decision rules making a pattern or creating a common thread. It can also be seen as the pattern or common thread related to the organization's activities which are derived from the policies, objectives and goals.

Kazmi (2008) defines strategy as the means to archiving objectives. It is seen as one of the most significant concepts to have emerged in the subject of management studies in the recent past. To Andrews (1980), strategy is the pattern of decision in a company that determines and reveals its objectives, purposes or goals, and defines the range of businesses the company is to pursue, the kind of economic and human organization it is or intends to be, and the nature of the economic and the non-economic contribution it intends to make to its shareholders, employees, customers and communities.

Strategies are business approaches to a set of competitive moves that are designed to generate a successful outcome (Rowe, 2008). It is seen as the determination of the basic long term goals and objectives of an enterprise, and the adoption of courses of action and the allocation of resources necessary for achieving these goals. It is primarily referred to as the roadmap laid out by an organization to ensure that an organization achieves the set targets in order to sustain and grow in an increasing competitive world. O'Regan, Sim and Gallear (2008) define strategy as an organization's main path of achieving overall corporate objectives and fundamental strategic goals, which in return create long term superior performance.

\subsubsection{Competitive strategy}

Since capability fosters competitive advantage of a strategy, what then is competitive strategy about? Porter (1986) believes that, in considering competitive strategy, two main issues have to be emphasized: industry attractiveness and competitive position. Competitive strategy must evolve from an understanding of the rules of competition that determine an industry's attractiveness. Mohsenzadeh and Ahmadian (2016) opine that competitive strategies mediate production capabilities in an organization. The ultimate goal of a firm's competitive strategy is to deal with or modify the rules to the advantage of the firm. Porter (1986) outlines an industry as having five competitive forces as - supplier power, buyer/customer power, substitute threat, exit/entry threat, and industry rivalry.

Kitching, Blackburn, Smallbone and Dixon (2009) affirm that the main motive of competitive strategy is to provide answers to two fundamental questions - i.e., what is the business doing, and how do firms compete in the rapid changing environment? Organizations adapt to environmental forces as they plan and carry out strategic activities. Predicting changes in the environment and acting proactively are all indices of an organisation's capabilities (Adeleke, Ogundele \& Oyenuga, 2008; Uvah, 2005). Strategies should be capable of producing intended results. Consistency of the strategy and its components should be well emphasized the need to gain competitive edge. This is why Oghojafor (2000) asserts that any strategy that does not provide a particular advantage to an organization against its rivals should be discarded.

\subsubsection{Strategy formulation process}

Formulating strategy requires sixth sense and rational reasoning (Oyewobi, Windapo, Cattel \& Rotimi, n. d.). The need for proactive thinking when formulating strategy is highly 
emphasized in the works of Barney (2001) as well as Priem \& Butler (2001). The following are the nine (9) steps taken at arriving at a welldefined strategy.

1. Formulating the company's mission including broad statements about mission

2. Conduct an analysis that reflects the company's internal conditions and capabilities, i.e. trying to analyse those things that are very strategic, that give the firm advantage over others. The essence of doing so, is to check resources, personnel, etc, to know how best to operate.

3. Assess the external factors

4. Analyzing the company's options by matching its resources with the external environment

5. Identify the most desirable options (strategies) by evaluating each of the options in likes of the company's mission

6. Select a set of long term objectives and grand strategies that would achieve the most desirable result.

7. Develop annual objectives and short term strategies that are compatible to the selected set of long term objectives and grand strategies

8. Implementing a strategic choice by means of budgeted resource allocation, in which the margin of tax, people, structure, technologies and reward system is emphasized.

9. Evaluate the success of the strategic process as a yardstick for future decision making. Trying to see if the aim of the strategy is successful or not. This would aid future application of such strategy.

Babafemi (2015) opines that strategy formulation process comprises three main elements that help turn an organisation's vision or mission into concrete achievable. They are namely strategic analysis, strategic choice and strategic implementation. The strategic analysis encompasses setting the organizations direction in terms of vision, mission and business environment. Strategic choice involves generating, evaluating and selecting the most appropriate strategy, while the strategy implementation consists of putting in place the relevant policies and formulating framework that will aid in translating chosen strategy into actionable forms.

\subsubsection{Levels of strategy}

The three organizational levels of strategy are those of the corporate, strategic business unit (SBU) and functional levels. They can be further simplified into different other types.

Corporate strategy level: This is seen as an overarching plan of action covering the various functions that are performed by different business units. It deals with the objectives of the company, allocation of resources and coordination of the business units for optimal performance. Corporate level strategies are basically about decisions related to managing and nurturing a portfolio of businesses. It helps to exercise the choice of direction that an organization adopts. According to Glueck \& Jauch (1984) there are four strategic alternatives: expansion, stability, retrenchment and any combination of these three.

Business level strategy: This is a comprehensive plan providing objectives for SBUs, allocation of resources among functional areas and coordination between them for making optimal contribution to the achievement of the corporate level objectives. They are the courses of action adopted by an organisation for each of its businesses separately, which serve identified customer groups and provide value to the customer by satisfaction of their needs. In the process, the organization uses its competencies to gain, sustain and enhance its strategic or competitive advantage.

Functional level strategy: This deals with a relatively restricted plan, providing objectives for certain functions, allocating resources among different operations within that functional area and coordination between them for optimal contribution to the achievement of the SBU and corporate level objectives. It is designed to achieve goals in the functional areas of business. It entails allocation of these resources to drive business and corporate strategies implementation.

\subsection{The place of capabilities in strategy} Strategy processes change under different transitions as from craft to mass production. Recently, it has become evident that the current landscape in many industries is one of ongoing, heightened levels of competition, which demand that a range of capabilities, including flexibility, delivery speed and innovation are in place. These approaches have emerged 
as a result of increased competition and greater levels of customer choice. Developing capabilities demands that a strategy be in place to achieve these requirements (Brown, 1998).

Successful competitors move quickly in and out of products, market and sometimes even entire businesses, a process more akin to an interactive video game than to chess. In such an environment, the essence of strategy is not the structure of a company's products and markets but the dynamics of its behaviour. The goal here is to identify and develop the hard-to-imitate organizational capabilities that distinguish a company from its competition in the eyes of companies. Stalk, Evans and Shulman (1992) believe that the key to transforming a set of individual business processes, is to connect them to real customer needs. A capability is strategic only when it begins and ends with the customer. Smallwood and Ulrich (2004) see capabilities as the collective skills, abilities and expertise of an organization that are the outcome of investments in staffing, training, compensation, communication and other human resources areas.

In some manner, they represent the ways that people and resources are brought together to accomplish work. According to Mikalef and Pateli (2017), dynamic capabilities facilitate as well as enhance competitive performance strategy in organizations. They form the identity and personality of the organization by defining what it is good at doing and, in the end, what it is. Here, we are looking at organizational capabilities and its essence in strategy formulation and implementation. An organization with an effective organizational capability range, gives a clear message of what the organization values now and in the foreseeable future. Through organizational capabilities in strategy, these benefits can be achieved (Ulrick \& Lake, 1991):

1. Greater stability

2. Individuals in the organization are more informed and empowered

3. There are reduced risks and stronger competitive advantages. Greater flexibility and innovation to respond to changing external influences

4. Acts as a strategic partner and improving stakeholder satisfaction

\subsection{Theoretical framework}

This paper is based on the resource based theory of the firm which tends to combine concepts from organisational economics and strategic management (Barney,1991). This theory emphasizes that the competitive advantage and superior performance of an organization can be explained by its distinctiveness of capabilities (Johnson, Scholes \& Whittington, 2008). The resource-based view (RBV) as a basis for competitive advantage lies primarily in the application of diverse valuable tangible or intangible resources at the firm's disposal. To transform a short run competitive advantage into a sustainable one, requires the heterogeneity of these resources. This effectively translates to valuable resources that are neither perfectly imitable nor substitutable without great effort (Barney, 1991).

Strategy is seen as a match an organization makes between its internal resources and skills and opportunities and risks created by its external environment (Olanipekun, Abioro, Akanni, Arulogun \& Rabiu, 2015). The resources and capabilities of a firm are the central consideration in formulating its strategy; they are the basis upon which a firm can establish its identity and frame its strategy. The key to a resource-based approach to strategy formulation is understanding the relationships between resources, capabilities, and competitive advantage. This theory has a common interest for management researchers and numerous writings. It explains the ability to deliver sustainable competitive advantage when resources are managed such that their outcomes cannot be imitated by competitors, which ultimately creates a competitive barrier. It emphasizes the fact that a firm's sustainable competitive advantage is reached by virtue of unique resources being rare, valuable, inimitable, unsubstitutable, as well as firm specific.

\section{CONCLUSION}

Organisations are said to be operating in a turbulent and hyper competitive environment, and it is their desire to continue to operate successfully by creating and delivering superior value to their customers while also learning how to adapt to a continuous and dynamic business environment. Strategies normally tend to be clear, to some extent, regarding their vision and high level outcomes when they are first developed. However, literature explored so far in the study, show that many formulated organizational strategies do not take into account the necessary capabilities needed. As a result, 
they may face significant difficulties in articulating their requirements in terms of clear objectives, actionable initiatives as well as precise and measurable performance indicators. It should therefore be the goal of every organization to reduce complexity where and whenever deemed necessary, and try to maximize their different capabilities therein.

\section{RECOMMENDATIONS}

The paper explored the position capability takes in the formulation and implementation of the strategies adopted in organisations. The practical implication shows that implementation success of any strategy resides within the capabilities of the firm and so practitioners must constantly sharpen the internal competences. Based on the findings made in the course of exploring, the subject matter, it is therefore recommended that:

1. The strategy formulation and implementation practices needs continuous and sustained supervision, improvement and adequate funding in view of it importance.

2. Organization should have a wellconceived strategic vision that must be communicated to all employees, because this amounts to strengthening its capabilities

3. It is imperative to emphasise that there be an organizational capability audit from time to time. This is to enable the organization check its ability to carry out any form of strategy when need arises.

\section{REFERENCES}

Adeleke, A., Ogundele, O. J. K and Oyenuga, O. O., 2008. Business policy and strategy. Lagos: Concept Publication Limited.

Andrews, K., 1980. The concept of corporate strategy. Irwin: Dow Jones

Babafemi, I. D., 2015. Corporate strategy, planning and performance evaluation: A survey of literature. Journal of Management Policies and Practices, 3, (1): $43-49$

Barney, J., 1991. Firm resources and sustained competitive advantage. Journal of Management, 17(1), 99-120
Barney, J. B., 2001. Is the resource based view a useful perspective for strategic management research? Yes. The Academy of Management Review, 26, (1): 41-56.

Bennis, W. G and Townsend, R., 1995. Reinventing leadership. New York: Collins Business Essential.

Brown, S., 1998. Manufacturing strategy, manufacturing seniority and plant performance in quality. International Journal of Operations and Production Management, 18, (6): 24-39.

Butuner, H., 2016. Before and after phases of strategic planning. Universal Journal of Management, 4, (3):120-129.

Dreyer, B and Gronhaug, K., 2004. Uncertainity, flexibility and sustainable competitive advantage. Journal of Business Research, 57, (1): 484-494.

Eistenhardt, K. M and Martin, J. A., 2000. Dynamic capabilities: What are they? Strategic Management Journal, 21(iii), 1105-1122

Gill, L and Delahaye, B., (n.d.) Building organizational capability: Your future, your business. Retrieved from www.business.otago.ac.nz

Glueck, W. F and Jauch, L. R., 1984. Business policy and strategic management. New York: McGraw-Hill.

Johnson, I., Scholes, $\mathrm{H}$ and Whittington, O., 2008. Exploring corporate strategy. London: Pearson Education Limited.

Kazmi, A., 2008. Strategic management and business policy. New Delhi: Tata McGraw-Hill Publishing Company Ltd.

Kelchner, L., 2016. The importance of organizational capability. Retrieved from www.smallbusiness.chrom.com

Kelly, K., 2015. Creating a collaborative organizational culture. Retrieved from www.excecdev.unc.edu. 
Kitching, J., Blackburn, R., Smallbone, D and

Dixon, R., 2009. Business strategies and performance during difficult economic conditions (project report), London UK. Department for Business Innovation and Skills (BIS).

Mikalef, P and Pateli, A., 2017. Information technology - enabled dynamic capabilities and their indirect effect on competitive performance: Findings from PLS-SEM and fsQCA. Journal of Business, 70, (1): $1-16$.

Moham, M., Voss, K. E and Jimenez, F. R., 2017. Managerial disposition and front end innovation success. Journal of Business Research, 70, (1): $193-201$.

Mohsenzadeh, M and Ahmadian, S., 2016. The mediating role of competitive strategies in the effect of firm competencies and export performance. Procedia Economics and Finance, 36, (1): 456 - 466.

Oghojafor, A., 2000. Strategic planning: A guide. Lagos: Malthouse Press Limited.

Olanipekun, W. D., Abioro, M. A., Akanni, L. F., Arulogun, O. O and Rabiu, R. O., 2015. Impact of strategic management on competitive advantage and organizational performance - evidence from Nigerian Bottling Company. Journal of Policy and Development Studies, 9, (2): 185-198.

O'Regan, N., Sim, M. A and Gallear, D., 2008. Leaders, loungers, laggards: The strategic planning environment performance relationship revisited in manufacturing SMES. Journal of Manufacturing Technology Management, 9, (1): 6-21.

Oyewobi, L. O., Windapo, A. O., Cattel, K. S and Rotimi, J. O. B., (n.d.). Impact of organizational structure and strategies on construction organisations performance. Retrieved from www.esearchgateway.ac.nz

Perrault, E., McClelland, R., Austin, C and Sieppert, J., 2011. Working together in collaborations: Successful process faction for community collaboration.
Administration in Social Work, 35, (3): 282-298.

Porter, M. E., 1986. Competitive strategy. New York: Harvard Business School Press

Priem, R. L and Buttler, J. E., 2001. Is the resource based view a useful perspective for strategic management research? Academy of Management Review, 26, (1): 22-40.

Rowe, J., 2008. Studying strategy. APS: Ventures Publishing.

Silva, A., 2016. What is leadership? Journal of Business Studies Quarterly, 8, (1): 1-5.

Sirinthon, K and Phapruke, U., 2010. Organization adaptability competency and its antecedents and consequences: An empirical investigation of hotel businesses in Thailand. Journal of International Business and Economics, 10, (2): 20-31.

Smallwood, N and Ulrich, D., 2004. Capitalizing on capabilities. Harvard Business Review, 40, (3): 119-127.

Stalk, G., Evans, P and Shulman, L. E., 1992. Competing on capabilities: The new rules of corporate strategy. Harvard Business Review, 10, (2): 57-69.

Ulrich, D and Lake, D., 1991. Organizational capability: Creating competitive advantage. Academy of Management Executive, 5, (1): 77-91.

Uvah, I. I., 2005. Problems, challenges and prospects in universities. Accessed from www.stratplanuniversities.pdf.

Veskaisri, K., Chan, P and Pollard, D., 2007. Relationship between strategic planning and SME success: Empirical evidence from Thailand. Retrieved from iceb.nccu.edu.tw/proceedings/APDSI/200 7/papers

Woodman, R. W., Sawyer, J. E and Griffin, R. W., 1993. Toward a theory of organizational creativity. The academy of Management Review, 18, (2): 293-321. 
